\title{
Effect of Stirring Energy, Temperature and Flux Composition on Hot Metal Dephosphorization Kinetics
}

\author{
Shin-ya KITAMURA, Toshihiro KITAMURA, ${ }^{1)}$ Kiyoshi SHIBATA, ${ }^{1)}$ Yoshimasa MIZUKAMI, ${ }^{2)}$ Susumu \\ MUKAWA $^{2)}$ and Junichi NAKAGAWA ${ }^{3)}$ \\ Yawata R \& D Laboratory, Central R \& D Bureau, Nippon Steel Corporation, Tobihata, Tobata-ku, Kitakyushu, Fukuoka-ken, \\ 804 Japan. $\quad 1$ ) Future \& Frontier Field Research Laboratory, Nippon Steel Corporation, Ida, Nakahara-ku, Kawasaki, \\ Kanagawa-ken, 211 Japan. $\quad$ 2) Nagoya R \& D Laboratory, Nippon Steel Corporation, Tokai-cho, Tokai, Aichi-ken, 476 \\ Japan. $\quad 3)$ Oita Works, Nippon Steel Corporation, Nishinosu, Oita, Oita-ken, 870 Japan.
}

(Received on April 25, 1991; accepted in final form on June 27, 1991)

In order to extend the applicability of a coupled reaction model to the hot metal dephosphorization process, evaluation method for unknown parameters was investigated. The following points were clarified.

(1) Mass transfer coefficient in metal phase was increased in proportion to $\dot{\varepsilon}^{1 / 2}$ and its activation energy was about $125 \mathrm{~kJ} / \mathrm{mol}$.

(2) Ratio of mass transfer coefficient in metal phase to slag phase did not clearly depend on stirring energy, temperature, or flux composition.

(3) Phenomenological rate parameter for $\mathrm{CO}$ evolution also did not clearly depend on stirring energy or flux composition but decreased with an increase in temperature.

(4) Activity coefficients of $\mathrm{FeO}$ and $\mathrm{P}_{2} \mathrm{O}_{5}$ in $\mathrm{CaF}_{2}$ and $\mathrm{CaCl}_{2}$ containing oxide slag were able to be estimated by a regular solution model in which the interaction energy was expressed as a function of the $\mathrm{CaF}_{2}, \mathrm{CaCl}_{2}$ content.

By the application of these results to the coupled reaction model, the change of concentration during the hot metal dephosphorization experiments was calculated without using a parameter fitting method.

KEY WORDS: mass transfer rate; stirring energy; activity coefficient; temperature dependence; hot metal pretreatment; decarburization rate.

\section{Introduction}

In the hot metal dephosphorization process, reductions of Fe-oxide, Mn-oxide, and oxidations of $\mathrm{C}, \mathrm{Fe}$, and $\mathrm{Mn}$ simultaneously take place, besides dephosphorization and desulphurization reactions. Some models have been proposed to analyze this complicated reaction system. These models are based on the assumptions that the mass transfer of each element is a rate controlling step and reactions at interface are always in a condition of equilibrium. ${ }^{1,2)}$ Among these models, the coupled reaction model ${ }^{1)}$ proposed by Ohguchi et al. had its effectiveness confirmed for many experimental conditions. ${ }^{3)}$ Also, this model was applied to the analysis of industrial scale experiments combined with fluid dynamics. ${ }^{4)}$ Nevertheless, the arbitrarity of the calculation method still remained. Because there were many unknown parameters in this model and these values had to be determined numerically in order to meet the calculation result to the experimentally obtained data (parameter fitting method). To solve this problem, the following three points have to be clarified.

(A) A method to estimate the equilibrium partition ratio in a wide slag composition range.

(B) A method to estimate the mass transfer coefficient in slag and metal phases as a function of stirring energy, slag composition, et al.

(C) A method of describing the decarburization reaction and the clarification of its determining factors.

Among these three points, regarding point (A), although some models to describe the activities of oxides for the multi-component slag system have been proposed, ${ }^{5,6)}$ the influences of fluoride and chloride have not been clarified yet. For point (B), although many equations to express the mass transfer coefficient in the metal phase have been proposed, ${ }^{7,8}$ its applicability to the industrial furnace has not been made clear yet. For the mass transfer coefficient in the slag phase, observed values were widely scattered ${ }^{9.10)}$ and its determining factor has not been clarified. For point (C), no reliable decarburization reaction model has been proposed yet, although the precise description of the reaction is important as it has a great influence on the oxygen potential at interface.

In order to solve these problems and extend the applicability of the coupled reaction model, this study was carried out to clarify the influences of various factors on the mass transfer coefficient, decarburization rate, and equilibrium partition ratio. 
Table 1. Experimental conditions of $70 \mathrm{~kg}$ scale tests.

\begin{tabular}{|c|c|c|c|c|c|c|c|}
\hline & \multicolumn{5}{|c|}{ Composition of hot metal $(\%)$} & \multirow{2}{*}{$\begin{array}{l}\text { Temperature } \\
\text { (K) }\end{array}$} & \multirow{2}{*}{$\begin{array}{c}\text { Ar gas flow rate } \\
\text { for stirring } \\
\left(\times 10^{-5} \mathrm{Nm}^{3} \cdot \mathrm{sec}^{-1}\right)\end{array}$} \\
\hline & $\mathrm{C}$ & $\mathrm{Si}$ & $\mathrm{Mn}$ & $\mathbf{P}$ & $S$ & & \\
\hline A & $4.0-4.5$ & $1.2-1.5$ & $<0.30$ & $<0.100$ & $<0.050$ & $1623-1873$ & $5-50$ \\
\hline B & $4.0-4.5$ & $.10-.15$ & $.30-.40$ & $.10-.15$ & $.03-.04$ & $1623-1823$ & $5-20$ \\
\hline
\end{tabular}

\section{Experimental Method}

\section{1. $70 \mathrm{~kg}$ Scale Experiment}

The experiments to clarify the influences of stirring energy, temperature on mass transfer coefficient and decarburization rate were carried out by using a $70 \mathrm{~kg}$ scale high frequency induction furnace.

Mass transfer in the metal phase can be considered as a rate controlling step of desiliconization reaction if the FeO content in slag is high since the partition ratio of $\mathrm{Si}$ is large. ${ }^{11)}$ The mass transfer coefficient in the metal phase was measured by hot metal desiliconization tests. After hot metal (about $70 \mathrm{~kg}$ ) was melted at an adequate temperature, a mixture of $\mathrm{Fe}_{2} \mathrm{O}_{3}$ (about $3 \mathrm{~kg}$ ) and $\mathrm{CaO}$ (about $0.3 \mathrm{~kg}$ ) reagents were added to the bath surface. At 15 to $60 \mathrm{sec}$ intervals, samples of metal and slag were taken. During the experiments, the metal bath was stirred by Ar gas through a porous brick at the bottom of the furnace. The experimental conditions are summarized in Table 1(A).

On the other hand, the influence of stirring energy and temperature on both the mass transfer coefficient in the slag phase and the decarburization rate were measured by hot metal dephosphorization tests. After the hot metal was melted, a mixture of reagents $(33.6 \mathrm{wt} \% \mathrm{CaO}-$ $9.3 \mathrm{wt} \% \mathrm{CaF}_{2}-57.1 \mathrm{wt} \% \mathrm{Fe}_{2} \mathrm{O}_{3}$ ) was added at $60 \mathrm{sec}$ in tervals for $600 \mathrm{sec}$ after the start of each experiment. The experimental period was $1200 \mathrm{sec}$ and the samples of metal and slag were taken at $240 \mathrm{sec}$ intervals. The experimental condition is shown in Table $\mathbf{1 ( B )}$.

In these experiments, bath temperature was controlled in the range of $\pm 10 \mathrm{~K}$ in an Ar atmosphere.

\section{2. $1 \mathrm{~kg}$ Scale Experiment}

The experiments to clarify the influence of slag composition on the mass transfer coefficient of the slag phase and on the decarburization rate were carried out by using a $1 \mathrm{~kg}$ scale Tammann furnace. After the hot metal was melted in fired $\mathrm{MgO}$ crucible at $1623 \mathrm{~K}$, a mixture of reagents was added at $180 \mathrm{sec}$ intervals for 20 times. The composition range of the flux and hot metal composition before experiments are shown in Table 2. In this table, $\mathrm{O}^{\prime}$ means the weight of oxygen in $\mathrm{FeO}$. The experimental time was $3600 \mathrm{sec}$. During this period, the metal samples were taken at $900 \mathrm{sec}$ intervals and the slag samples were taken at $1800 \mathrm{sec}$ intervals. Bath temperature was measured at $900 \mathrm{sec}$ intervals and controlled in the range of $\pm 10 \mathrm{~K}$ in an $\mathrm{Ar}$ atmosphere.

\section{Experimental Results and Discussion}

\subsection{Coupled Reaction Model}

In the coupled reaction model, the reactions shown in
Table 2. Experimental conditions of $1 \mathrm{~kg}$ scale dephosphorization tests.

\begin{tabular}{|c|c|c|c|c|c|}
\hline \multicolumn{5}{|c|}{ Composition of hot metal (\%) } & \multirow{2}{*}{$\begin{array}{l}\text { Temperature } \\
\text { (K) }\end{array}$} \\
\hline $\mathrm{C}$ & $\mathrm{Si}$ & $\mathrm{Mn}$ & $\mathrm{P}$ & $S$ & \\
\hline $4.0-4.5$ & $<0.02$ & $.30-.40$ & $.10-.15$ & $.03-.04$ & 1623 \\
\hline \multicolumn{6}{|c|}{ Composition of flux $(\%)$} \\
\hline \multicolumn{2}{|c|}{$\mathrm{CaO} / \mathrm{SiO}_{2}$} & $\mathrm{CaF}_{2} / \mathrm{CaO}$ & \multicolumn{2}{|c|}{$\mathrm{CaCl}_{2} / \mathrm{CaO}$} & $\mathrm{CaO} / \mathrm{O}^{\prime}$ \\
\hline \multicolumn{2}{|c|}{$2.00-4.05$} & $0.10-0.30$ & \multicolumn{2}{|c|}{$0.00-0.07$} & $0.87-1.98$ \\
\hline
\end{tabular}

Eq. (1) are considered and the reaction rate of Eq. (2) is expressed by Eq. (3) on the assumption that the mass transfer of the slag and the metal phase is a rate controlling step. For decarburization, a phenomenological rate parameter for $\mathrm{CO}$ evolution $\left(G_{\mathrm{CO}}\right)$ is introduced and the reaction rate is expressed by $\mathrm{Eq}$. (4).

$$
\begin{aligned}
& {[\mathrm{Si}]+2[\mathrm{O}]=\left(\mathrm{SiO}_{2}\right)} \\
& \mathrm{Mn}+[\mathrm{O}]=(\mathrm{MnO}) \\
& \mathrm{Fe}+[\mathrm{O}]=(\mathrm{FeO}) \\
& {[\mathrm{P}]+2.5[\mathrm{O}]=\left(\mathrm{PO}_{2.5}\right)} \\
& {[\mathrm{C}]+\quad[\mathrm{O}]=\mathrm{CO}} \\
& {[\mathrm{M}]+n \cdot[\mathrm{O}]=\left(\mathrm{MO}_{n}\right)}
\end{aligned}
$$$$
J_{\mathrm{M}}=\left\{k_{m} \cdot \rho_{m} /\left(100 \cdot N_{\mathrm{M}}\right)\right\} \cdot\left\{[\% \mathrm{M}]^{b}-[\% \mathrm{M}]^{i}\right\}
$$$$
=\left\{k_{s} \cdot \rho_{s} /\left(100 \cdot N_{\mathrm{MO}_{n}}\right)\right\} \cdot\left\{\left(\% \mathrm{MO}_{n}\right)^{i}-\left(\% \mathrm{MO}_{n}\right)^{b}\right\}
$$$$
J_{\mathrm{C}}=\left\{k_{m} \cdot \rho_{m} /\left(100 \cdot N_{\mathrm{C}}\right)\right\} \cdot\left\{[\% \mathrm{C}]^{b}-[\% \mathrm{C}]^{i}\right\}
$$$$
=G_{\mathrm{CO}} \cdot\left(P_{\mathrm{CO}}^{i} / P_{1}-1\right)
$$

The equations for the equilibrium partition ratio of each reaction at interface can be expressed by Eq. (5) (effective equilibrium constant). From these equations and the electrical neutrality equation, the change of concentration for each element in the metal and the slag phase can be calculated.

$$
\begin{aligned}
E_{\mathrm{M}} & =\left(\% \mathrm{MO}_{n}\right)^{i} /\left([\% \mathrm{M}]^{i} \cdot a_{\mathrm{O}}^{i n}\right) \\
& =\left(100 \cdot C_{t} \cdot N_{\mathrm{MO}_{n}} \cdot f_{\mathrm{M}} \cdot K_{\mathrm{M}}\right) /\left(\rho_{s} \cdot \gamma_{\mathrm{MO}_{n}}\right)
\end{aligned}
$$

The quantitative information of the influences of various factors on the mass transfer coefficient in the metal and the slag phase, decarburization rate and equilibrium partition ratio are necessary to solve these equations.

\subsection{Effective Equilibrium Constant}

The equilibrium constant and the activity coefficient of each component in both metal and slag phase have 

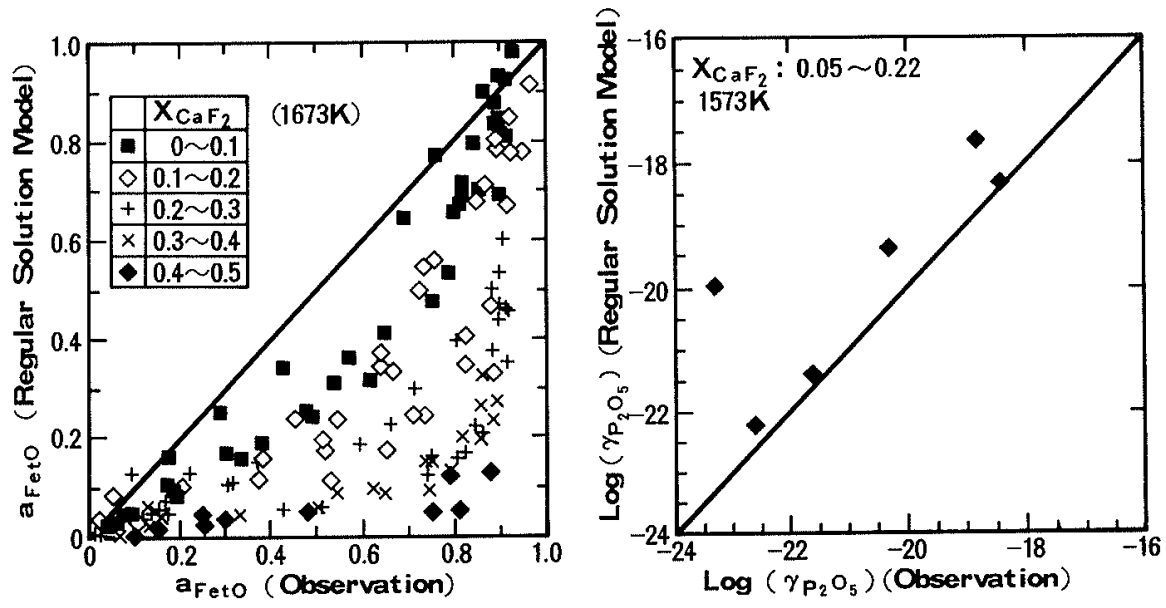

Fig. 1. Comparison of observed and calculated values for $a_{\mathrm{FcO}}$ and $\gamma_{\mathrm{P}_{2} \mathrm{O}_{5}}$.

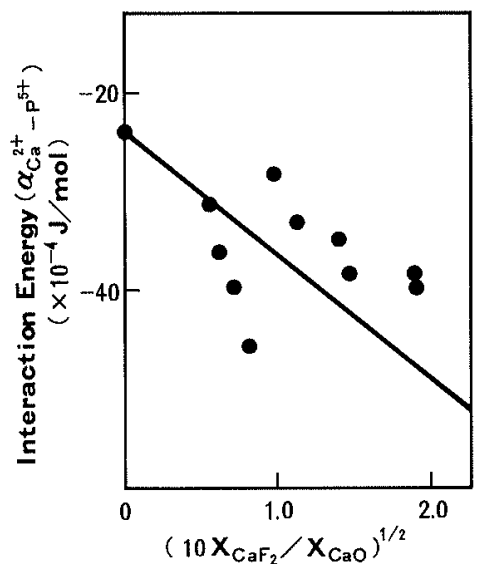

Fig. 2. Relation between interaction energy of $\mathrm{Ca}^{2+}+\mathrm{P}^{5+}$ and $\mathrm{CaF}_{2}$ content in slag.

to be evaluated to determine the effective equilibrium constant. Among these values, the equilibrium constant and the activity coefficient of each component in the metal phase can be calculated based on the various data already reported. ${ }^{12)}$ On the other hand, although the activity coefficient of each component in the slag phase can be calculated by the regular solution model proposed by Ban-ya et al., ${ }^{6}{ }^{6}$ the influence of fluoride and chloride can not be taken into consideration. In Fig. 1, a comparison between the observed values by Iwase et al. ${ }^{13)}$ and the calculated values by the regular solution model for $\mathrm{FeO}$ and $\mathrm{P}_{2} \mathrm{O}_{5}$ in hot metal dephosphorization slag are shown. In this calculation, the concentration of $\mathrm{CaF}_{2}$ and $\mathrm{CaCl}_{2}$ were considered to be zero. From this figure, no good correlation can be seen.

Then, the interaction energy of $\mathrm{Ca}^{2+}-\mathrm{Fe}^{2+}$ and $\mathrm{Ca}^{2+}-\mathrm{P}^{5+}$ were evaluated numerically in order to meet the observed values of the activity coefficient for $\mathrm{CaF}_{2}$ and $\mathrm{CaCl}_{2}$ containing slag ${ }^{13-15)}$ to the calculated values by the regular solution model. Figure 2 shows the relation between $\mathrm{CaF}_{2}$ content and the interaction energy of $\mathrm{Ca}^{2+}-\mathrm{P}^{5+}\left(\alpha\left(\mathrm{Ca}^{2+}-\mathrm{P}^{5+}\right)\right)$. The interaction energy decreased as the increase of $\mathrm{CaF}_{2}$ content and the linear relation was obtained between $\alpha\left(\mathrm{Ca}^{2+}-\mathrm{P}^{5+}\right)$ and $\left(10 \cdot X_{\mathrm{CaF}_{2}} / X_{\mathrm{CaO}}\right)^{1 / 2}$. By the similar method, a linear relation between $\alpha\left(\mathrm{Ca}^{2+}-\mathrm{P}^{5+}\right)$ and $\left(10 \cdot X_{\mathrm{CaCl}_{2}} / X_{\mathrm{CaO}^{2}}\right)^{2}$ was obtained. Figure 3 shows the relation between $\alpha\left(\mathrm{Ca}^{2+}\right.$

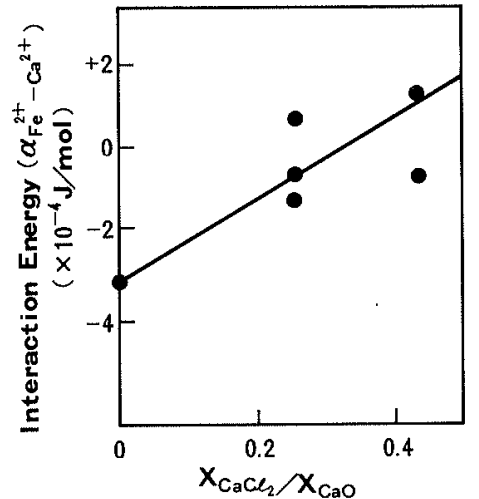

Fig. 3. Relation between interaction energy of $\mathrm{Fe}^{2+}-\mathrm{Ca}^{2+}$ and $\mathrm{CaCl}_{2}$ content in slag.

$\left.\mathrm{Fe}^{2+}\right)$ and $\left(X_{\mathrm{CaCl}_{2}} / X_{\mathrm{CaO}}\right)$. The interaction energy increased as the increase of $\mathrm{CaCl}_{2}$ content and the linear relation was obtained. Also, good linear relation was obtained between $\alpha\left(\mathrm{Ca}^{2+}-\mathrm{Fe}^{2+}\right)$ and $\left(X_{\mathrm{CaF}_{2}} / X_{\mathrm{CaO}}\right)$.

By these method, Eqs. (6) and (7) were obtained and the evaluation of the activity coefficient of $\mathrm{P}_{2} \mathrm{O}_{5}$ and $\mathrm{FeO}$ for $\mathrm{CaF}_{2}$ and $\mathrm{CaCl}_{2}$ containing slag became possible.

$$
\begin{aligned}
\alpha\left(\mathrm{Ca}^{2+}-\mathrm{Fe}^{2+}\right)= & -31400+62400 \cdot X_{\mathrm{CaF}_{2}} / X_{\mathrm{CaO}} \\
& +96000 \cdot X_{\mathrm{CaCl}_{2}} / X_{\mathrm{CaO}} \ldots \ldots \ldots \ldots \ldots \ldots \ldots . . .16 \\
\alpha\left(\mathrm{Ca}^{2+}-\mathrm{P}^{5+}\right)= & -250000-127700 \cdot\left(10 \cdot X_{\mathrm{CaF}_{2}} / X_{\mathrm{CaO}}\right)^{1 / 2} \\
& -23550 \cdot\left(10 \cdot X_{\mathrm{CaCl}_{2}} / X_{\mathrm{CaO}}\right)^{2} \ldots \ldots \ldots \ldots \ldots . . . \ldots
\end{aligned}
$$

\subsection{Mass Transfer Coefficient of Metal Phase}

The linear relation between $\log [\% \mathrm{Si}]$ and time was observed from the results of hot metal desiliconization tests, in which $(\mathrm{FeO})$ in slag was high. Then the mass transfer coefficient in the metal phase $\left(k_{m}\right)$ was calculated by Eq. (8).

$$
k_{m}=\{-d(\log [\% \mathrm{Si}]) / d t\} \cdot(V \mid A)
$$

In Fig. 4, temperature dependence of $k_{m}$ is shown. From this result, the activation energy was evaluated as about $125 \mathrm{~kJ} / \mathrm{mol}$. This value was larger than the activation energy of diffusion coefficients for many elements in molten iron and steel which were reported as $17-105 \mathrm{~kJ} / \mathrm{mol}^{16)}$

The influence of the stirring energy $(\dot{\varepsilon})$ calculated by 


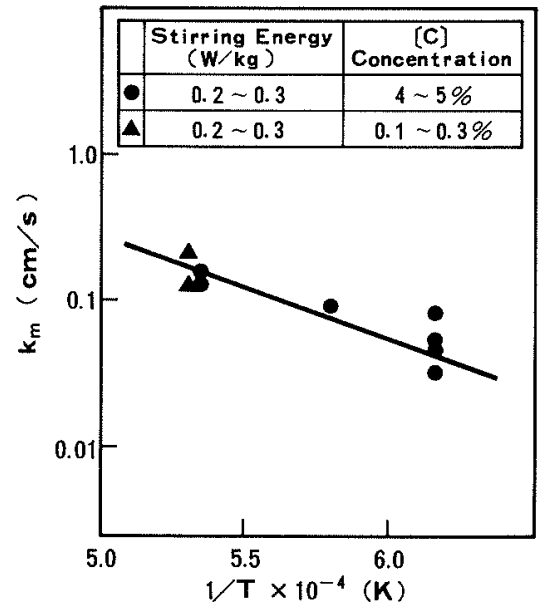

Fig. 4. Temperature dependence of mass transfer coefficient in metal phase.

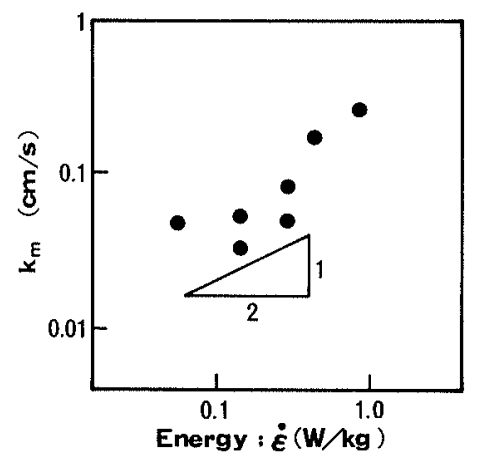

Fig. 5. Relation between stirring energy and mass transfer coefficient of metal phase.

the equation by Mori et al. ${ }^{17)}$ on $k_{m}$ is shown in Fig. 5 . It can be seen that $k_{m}$ increased in proportion to $\dot{\varepsilon}^{1 / 2}$. In order to compare these values to the values of industrial scale experiments, the results of desiliconization tests which were carried out by the top addition method of $\mathrm{Fe}$ oxide in various size furnaces were analyzed. $\mathrm{As}(\mathrm{FeO})$ content in slag varied from 20 to $40 \%$ in these experiments, the mass transfer in the metal phase was able to be considered as a rate controlling step. Figure 6 shows the comparison between observed values of $k_{m}$ and the parameter which express the influence of stirring energy and dimensions of furnace on $k_{m}$ proposed by Sawada et al ${ }^{8}{ }^{8}$ From this figure, good correspondence can be observed, especially between the results of induction furnace, $6 \mathrm{t}$ ladle and $100 \mathrm{t}$ ladle. It can be found that $k_{m}$ can be expressed by this parameter for not only small scale experiments but also industrial scale furnaces.

According to these results, the mass transfer coefficient of the metal phase can be expressed mathematically by Eq. (9).

$$
\begin{aligned}
\log k_{m}= & 1.98+0.5 \cdot \log \left(\dot{\varepsilon} \cdot H^{2} / L / 100\right) \\
& -(125000 /(R \cdot T)) / 2.3 \quad \ldots \ldots
\end{aligned}
$$

Concerning the influence of stirring intensity on $k_{m}$, it was reported that if the injection gas flow rate $(Q)$ increased over a critical value, the relationship between $k_{m}$ and $Q$ changed since the mixing of slag particles into

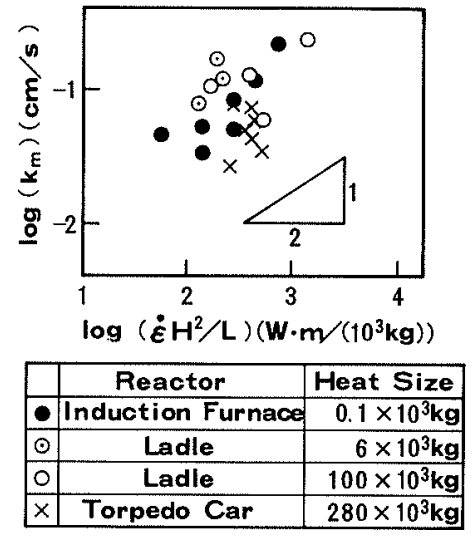

Fig. 6. Influence of stirring energy and furnace scale on mass transfer coefficient of metal phase.

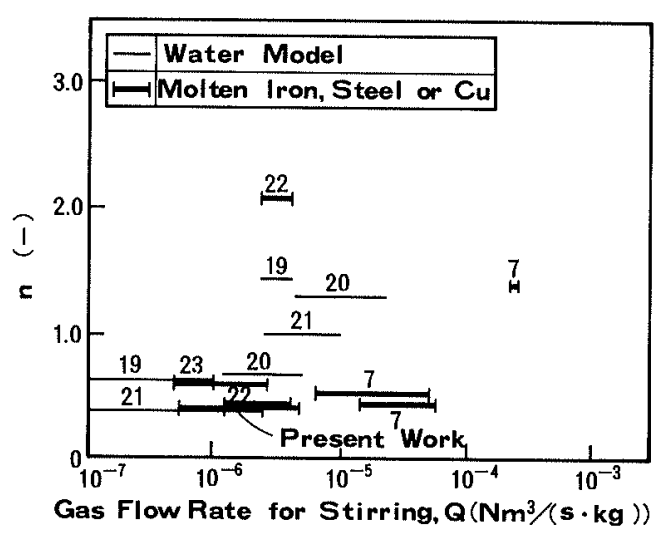

Fig. 7. Relation between gas flow rate for stirring and $n$-value for various experiments. (Numbers in figure correspond to reference numbers.)

the metal phase had begun to take place. ${ }^{18)}$ Figure 7 shows the relation between $Q$ and $n$ for previously reported data. In this figure, $n$ indicates the value of the power when the influence of $Q$ on $k_{m}$ is represented as shown in Eq. (10). ${ }^{18)}$

$$
k_{m} \propto Q^{n}
$$

From this figure, it is found that in the water models, $n$ begins to increase when $Q$ exceeds $1.5 \times 10^{-6}$ $\mathrm{Nm}^{3} /(\mathrm{sec} \cdot \mathrm{kg})$ but in the experiments with molten iron, steel and $\mathrm{Cu}, n$ remains about 0.5 , although $Q$ increases to a large value range except in one result. ${ }^{22}$ The reason for this difference can be considered as the following.

(1) The mixing of slag particles in the molten iron is difficult to accomplish because the critical value for the molten iron and slag system is 3 times larger than that for the water and liquid paraffin system according to the equation for the critical flow rate of slag mixing by Asai et al. ${ }^{18)}$

(2) As the difference in density between the two phases is large, the emulsion of the slag and metal system is unstable compared to the emulsion of the water and liquid paraffin system.

\subsection{Mass Transfer Coefficient of Slag Phase and De- carburization Rate}

The mass transfer coefficient of the slag phase $\left(k_{s}\right)$ and decarburization rate constant was estimated by a cal- 

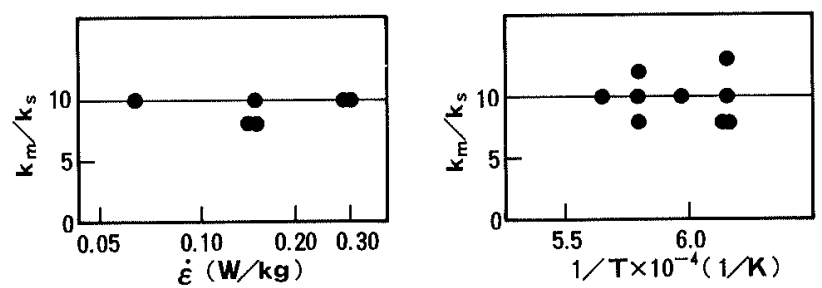

Fig. 8. Influence of temperature and stirring energy on the ratio of mass transfer coefficient in metal and slag phases.
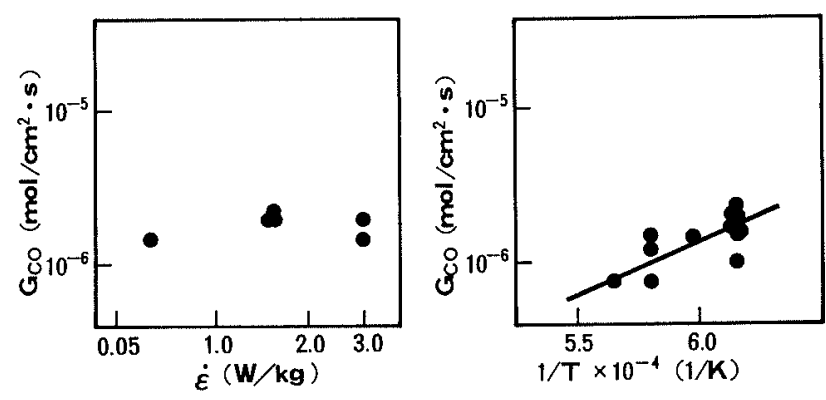

Fig. 9. Influence of temperature and stirring energy on rate constant of $\mathrm{CO}$ evolution.

culation of the coupled reaction model. In this model, when the effective equilibrium constant is evaluated by the method explained in Sec. 3.2 and the mass transfer coefficient of the metal phase is calculated by Eq. (9), only $k_{s}$ and $G_{\mathrm{CO}}$ remains as the unknown parameters. An almost unique combination of $k_{s}$ and $G_{\mathrm{CO}}$ can be determined if these values are selected numerically in order to meet the calculated values to the experimentally obtained dephosphorization curve and $\mathrm{FeO}$ content in slag. Using this procedure, the arbitrarity for the evaluation of these parameters can be avoided and the values of $k_{s}, G_{\mathrm{CO}}$ can be evaluated.

The influences of temperature and stirring energy on the ratio of $k_{m}$ to $k_{s}\left(k_{m} / k_{s}\right)$ is shown in Fig. 8. No obvious dependence was observed. This result means that the dependence of $k_{m}$ and $k_{s}$ on temperature and stirring energy is almost the same.

For temperature dependence, this result does not correspond to the results in which the activation energy of the diffusion coefficient in slag and metal is different. ${ }^{16)}$ In this experiment, the change in slag temperature would be smaller than that in metal temperature, as an induction furnace was used. As the effect of smaller temperature change in slag phase and the effect of larger activation energy of diffusion coefficient in slag phase were cancelled, the same temperature dependence of $k_{m}$ and $k_{s}$ would be obtained.

For the dependence of $k_{s}$ on stirring energy, few observations have been reported. One of the authors has obtained a similar result for the mass transfer rate of oxide $\mathrm{Cr}$ in smelting reduction slag ${ }^{24)}$ but more experiments would be necessary for various slag conditions.

The influences of temperature and stirring energy on $G_{\mathrm{CO}}$ are shown in Fig. 9. It can be seen that $G_{\mathrm{CO}}$ is reduced as the temperature increases, although the dependence for stirring energy was not clear. As the activation energy
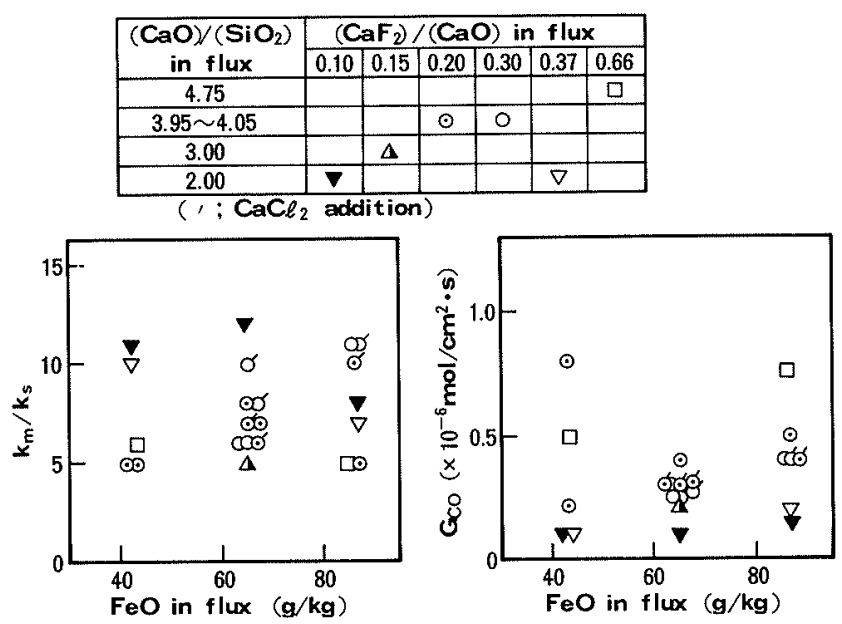

Fig. 10. Influence of flux composition on rate constant of $\mathrm{CO}$ evolution and the ratio of mass transfer coefficient in metal and slag phases.

Table 3. Summary of the evaluation methods for each parameter.

\begin{tabular}{|c|c|}
\hline \multicolumn{2}{|r|}{ Mass transfer coefficient } \\
\hline Metal phase & $\begin{aligned} \log \left(k_{m}\right)= & 1.98+0.5 \cdot \log \left(\dot{\varepsilon} \cdot H^{2} / L / 100\right) \\
& -(125000 /(R \cdot T)) / 2.3\end{aligned}$ \\
\hline Slag phase & $\begin{array}{l}\left(k_{m} / k_{s}\right)=5-10 \\
\text { (Independent on temperature, stirring condition, } \\
\text { slag composition) }\end{array}$ \\
\hline \multicolumn{2}{|c|}{ Effective equilibrium constant (Activity coefficient of oxide) } \\
\hline $\mathrm{P}_{2} \mathrm{O}_{5}$ & $\begin{aligned} \alpha\left(\mathrm{Ca}^{2+}+\mathrm{P}^{5+}\right)= & -60000-30500 \cdot\left(10 \cdot X_{\mathrm{CaF}_{2}} / X_{\mathrm{CaO}}\right)^{1 / 2} \\
& -5625 \cdot\left(10 \cdot X_{\left.\mathrm{CaCl}_{2} / X_{\mathrm{CaO}}\right)^{2}}\right.\end{aligned}$ \\
\hline $\mathrm{FeO}$ & $\begin{aligned} \alpha\left(\mathrm{Fe}^{2+}-\mathrm{Ca}^{2+}\right)= & -7500+14900 \cdot X_{\mathrm{CaF}_{2}} / X_{\mathrm{CaO}} \\
& +23000 \cdot X_{\mathrm{CaCl}_{2} / X_{\mathrm{CaO}}}\end{aligned}$ \\
\hline \multicolumn{2}{|r|}{ Decarburization } \\
\hline$G_{\mathrm{CO}}$ & $\begin{array}{l}\text { Fitting parameter (Depend on temperature) } \\
\text { (Independent on stirring condition, slag composition) }\end{array}$ \\
\hline
\end{tabular}

of $G_{\mathrm{CO}},-150 \mathrm{~kJ} / \mathrm{mol}$ was obtained.

On the other hand, the influence of flux composition on $k_{m} / k_{s}$ and $G_{\mathrm{CO}}$ is shown in Fig. 10. During these experiments, slag composition was not widely changed as the flux was added semicontinuously at $180 \mathrm{sec}$ intervals. From this figure, no obvious dependence can be found for $k_{m} / k_{s}$ and $G_{\mathrm{CO}}$. Mori ${ }^{25)}$ reported that during the increase in slag viscosity from 0.01 to $0.1 \mathrm{~N} \cdot \mathrm{sec} / \mathrm{m}^{2}$ ( 0.1 to 1.0 poise), $k_{m} / k_{s}$ increased from about 1.0 to 10 but if the slag viscosity increased over $0.1 \mathrm{~N} \cdot \mathrm{sec} / \mathrm{m}^{2}$, $k_{m} / k_{s}$ did not increase and became a constant value (about 10). By another experiments, ${ }^{26)}$ it was measured that the range of viscosity of hot metal dephosphorization slag was from 1 to $10 \mathrm{~N} \cdot \mathrm{sec} / \mathrm{m}^{2}$. The results shown in Fig. 10 would be in good agreement with the results obtained by Mori, although viscosity of slag used in the present experiment was not measured.

\section{Application to Coupled Reaction Model}

The above evaluation method for each parameter is summarized in Table 3. Figure $\mathbf{1 1}$ shows the corre- 


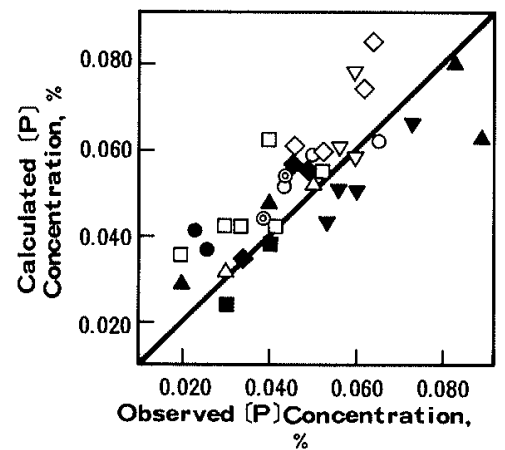

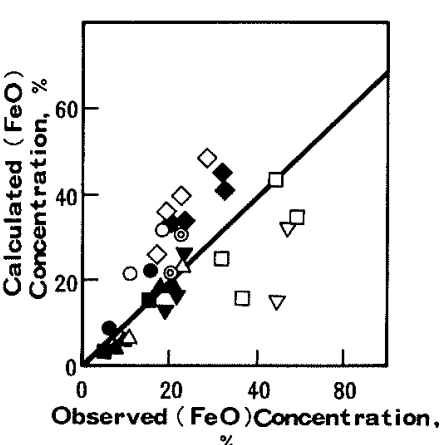

$\%$

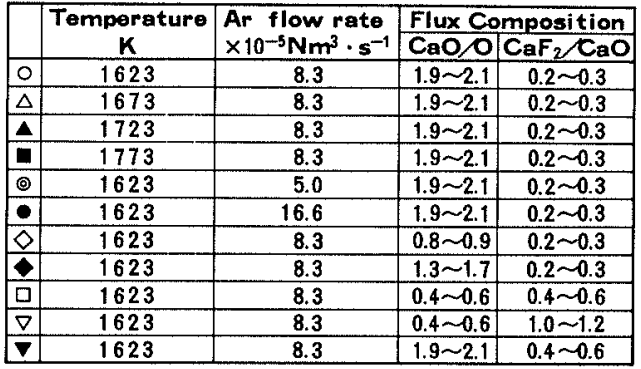

Fig. 11. Comparison of observed and calculated values for $70 \mathrm{~kg}$ scale experiments. spondence between observed values and calculated values for various experimental conditions. In these calculations, $G_{\mathrm{CO}}$ was determined by the parameter fitting method for one experimental result under a standard condition and only changed by temperature. The other parameters were evaluated by the method shown in Table 3 . By this procedure, when $G_{\mathrm{CO}}$ was determined by the parameter fitting method for one of the experimental results, the coupled reaction model could be calculated for the other experimental conditions without using the parameter fitting method. From the good correspondence shown in this figure, the applicability of this evaluation method was considered to be confirmed.

\section{Conclusion}

In order to clarify the evaluation method of various parameters of the coupled reaction model, the influence of various factors on the mass transfer coefficient, decarburization rate and effective equilibrium constant were investigated. The following points were clarified.

(1) Mass transfer coefficient in the metal phase could be expressed by the following equation:

$$
\begin{aligned}
\log k_{m}= & 1.98+0.5 \cdot \log \left(\dot{\varepsilon} \cdot H^{2} / L / 100\right) \\
& -(125000 /(R \cdot T)) / 2.3
\end{aligned}
$$

(2) The ratio of mass transfer coefficient in the metal to the slag phases did not clearly depend on stirring energy, temperature, or flux composition.

(3) Phenomenological rate parameter for $\mathrm{CO}$ evolution also did not clearly depend on stirring energy or flux composition but decreased with increase of temperature.

(4) Activity coefficients of $\mathrm{FeO}$ and $\mathrm{P}_{2} \mathrm{O}_{5}$ in $\mathrm{CaF}_{2}$ and $\mathrm{CaCl}_{2}$ containing oxide slag could be estimated by a regular solution model in which the interaction energy was expressed as a function of $\mathrm{CaF}_{2}$ and $\mathrm{CaCl}_{2}$ content.

\section{Nomenclature}

$a_{\mathrm{O}}^{i}$ : Henrian activity of oxygen at slag/metäl interface on the weight percent basis

$A$ : geometrical area of slag/metal interface $\left(\mathrm{cm}^{2}\right)$

$C_{t}$ : total molar concentration in slag $\left(\mathrm{mol} \cdot \mathrm{cm}^{-3}\right)$

$f:$ Henrian activity coefficient

$G_{\mathrm{CO}}$ : phenomenological rate parameter for $\mathrm{CO}$ evolution $\left(\mathrm{mol} \cdot \mathrm{cm}^{-2} \cdot \mathrm{sec}^{-1}\right)$

$H$ : bath depth (cm)
$J:$ molar flux density $\left(\mathrm{mol} \cdot \mathrm{cm}^{-2} \cdot \mathrm{sec}^{-1}\right)$

$K$ : equilibrium constant

$k$ : mass transfer coefficient $\left(\mathrm{cm} \cdot \mathrm{sec}^{-1}\right)$

$L:$ diameter of furnace $(\mathrm{cm})$

$N$ : molecular weight $\left(\mathrm{g} \cdot \mathrm{mol}^{-1}\right)$

$P_{\mathrm{CO}}^{i}$ : super saturated pressure of $\mathrm{CO}$ gas at reaction interface $(\mathrm{Pa})$

$P_{1}:$ pressure of atmosphere $(\mathrm{Pa})$

$Q:$ injected gas flow rate $\left(\mathrm{Nm}^{3} \cdot \mathrm{sec}^{-1} \cdot \mathrm{kg}^{-1}\right)$

$T:$ temperature $(\mathrm{K})$

$t:$ time $(\mathrm{sec})$

$V:$ volume of metal $\left(\mathrm{cm}^{3}\right)$

$X$ : mole fraction

$\alpha$ : interaction energy $(\mathrm{J} / \mathrm{mol})$

$\gamma$ : activity coefficient with respect to the pure substance as standard state

$\dot{\varepsilon}: \quad$ stirring energy $\left(\mathrm{W} \cdot \mathrm{kg}^{-1}\right)$

$\rho:$ density $\left(\mathrm{g} \cdot \mathrm{cm}^{-3}\right)$

Subscript

$m:$ metal

$s:$ slag

Superscript

$b$ : bulk

$i$ : interface

\section{REFERENCES}

1) S. Ohguchi, D. G. C. Robertson, B. Deo, P. Grieveson and J. H. E. Jeffes: Ironmaking Steelmaking, 11 (1984), 202.

2) N. Shinozaki, K. Mori and Y. Kawai: Tetsu-to-Hagané, 68 (1982), 72.

3) I. Sawada, T. Ohashi, H. Kajioka, K. Umezawa and K. Arima: Tetsu-to-Hagané, 70 (1984), Al78.

4) T. Kitamura, K. Shibata, I. Sawada and S. Kitamura: Proc. of The Sixth Int. Iron and Steel Cong., Vol. 3, ISIJ, Tokyo, (1990), 50.

5) H. Gaye and J. Welfringer: Proc. of The Second Int. Symp. on Metallurgical Slag and Flux, TMS, Pennsylvania, (1985), 357.

6) S. Ban-ya and M. Hino: Tetsu-to-Hagané, 74 (1988), 1701.

7) M. Hirasawa, K. Mori, M. Sano, A. Hatanaka, Y. Shimatani and Y. Okazaki: Tetsu-to-Hagané, 73 (1987), 1343.

8) I. Sawada, T. Ohashi and H. Kajioka: Tetsu-to-Hagané, 70 (1984), S160, S161.

9) Han Ye-Tao, M. Sano, M. Hirasawa and K. Mori: Tetsu-toHagané, 74 (1988), 61.

10) K. Mori, Y. Fukami and Y. Kawai: Trans. Iron Steel Inst. Jpn., 28 (1988), 315.

11) K. Narita, T. Makino, H. Matsumoto, A. Hikosaka and J. Katsuta: Tetsu-to-Hagané, 69 (1983), 1722. 
12) Steelmaking Data Sourcebook Revised Edition, The 19th Committee (Steelmaking), The Japan Society for the Promotion of Science (JSPS), Tokyo, (1984).

13) M. Iwase, E. Ichise, N. Yamada and N. Nishida: Trans. Met. Soc. AIME, 4 (1984), 47.

14) S. R. Simeonov and N. Sano: Trans. Iron Steel Inst. Jpn., 25 (1985), 1031.

15) M. Muraki, H. Fukushima and N. Sano: Tetsu-to-Hagané, 71 (1985), 693.

16) K. Nagata, N. Sata and K. Goto: Tetsu-to-Hagané, 68 (1982), 1694.

17) K. Mori and M. Sano: Tetsu-to-Hagané, 67 (1981), 672.

18) S. Asai, M. Kawachi and I. Muchi: SCANJECTIII, MEFOS,
Lulea, (1983), 12.

19) S. H. Kim and R. J. Fruehan: Metall. Trans., 18B (1987), 381.

20) Y. Ohga, S. Taniguchi and A. Kikuchi: Tetsu-to-Hagané, 71 (1985), S897

21) K. Nakanishi and T. Fujii: Tetsu-to-Hagané, 59 (1973), S460.

22) J. Ishida, K. Yamaguchi, S. Sugiura, K. Yamano, S. Hayakawa and N. Demukai: Denki Seiko (Electr. Furn. Steel), 52 (1981), 2.

23) K. Umezawa, K. Nisugi, R. Arima and H. Matsunaga: Tetsu-to-Hagané, 67 (1981), S182.

24) S. Kitamura, T. Arai, M. Matsuo and K. Okohira: Proc. of The Sixth Int. Iron and Steel Cong., Vol. 1, ISIJ, Tokyo, (1990), 139.

25) K. Mori: private communication, Kyushu University, (1990).

26) S. Kitamura: to be submitted to ISIJ Int. 